\title{
O coronel Ponciano como sujeito discursivo, em O Coronel e o Lobisomem
}

\author{
Cleudemar Alves Fernandes \\ Universidade Federal de Uberlândia
}

\section{Abstract}

We consider that the subject results from a complex frame-work: there is a "self" which is the result of "other selves".

In that sense we developed in this study a discourse analysis of the protagonist of the novel O Coronel e o Lobisomem giving attention to the linguistic aspects that mark the subjectivity presence in the discourse and to the aspects that mark the exterior presence in the discourse. 
“... à ne plus traiter les discours comme des ensembles de signes (...) mais comme des pratiques qui forment systématiquement les objets dont ils parlent. Certes, les discours sont faits de signes; mais ce qu'ils font, c'est plus que d'utiliser ces signes pour désigner des choses. (...) C'est ce 'plus' qu'il faut faire apparaître..."

Foucault (1969).

\section{CONSIDERAÇÕES INICIAIS}

$\mathrm{V}$

isando a obter uma compreensão do discurso do coronel Ponciano de Azeredo Furtado, protagonista e narrador do romance O Coronel e Lobisomem, analisá-lo-emos tomando como ponto focal dois estudiosos que se encontram em oposição. $\mathrm{O}$ primeiro a ser ressaltado, Benveniste, afirma ser o discurso centrado no "eu", na subjetividade do locutor; o segundo, Bakhtin, afirma ser o discurso centrado no exterior, em um "outro" social.

Recorremos a algumas teorias formuladas por esses estudiosos para nos auxiliarem na busca de uma compreensão da constituição discursiva da personagem em questão, que é também narrador da história.

Dessa maneira, recorreremos a um conjunto de estudos lingüísticos que tratam das condutas lingüísticas individuais. Procuraremos caracterizar o sujeito social em contraste com o grupo dos sujeitos falantes em uma mesma comunidade lingüística global.

No que concerne especificamente ao discurso do sujeito, mais especificamente do sujeito coronel Ponciano de Azeredo Furtado, analisá-lo-emos sob dois enfoques teóricos, conforme mencionamos. Contudo, não pretendemos definir o sujeito discursivo com base em um dos estudiosos apenas. O que temos são focalizações de certos aspectos do funcionamento discursivo.

Procederemos, portanto, à apreensão do coronel Ponciano de Azeredo Furtado como sujeito através dos enunciados por ele produzidos. 
Devemos considerar ainda que, por alguns momentos, encontramos rápidos diálogos entre as personagens no romance em questão apresentados pelo narrador, o qual estará utilizando o discurso direto. Há, portanto, a aparição de um segundo locutor. O emprego desta modalidade de discurso se caracteriza pela repro-dução literal de enunciados citados. Segundo Maingueneau (1993: 85), podemos ver no discurso direto uma espécie de teatralização, pois "o locutor é que fala, podendo, assim, apresentar enunciados de enunciadores não presentes". O narrador - locutor responsável - ao dar a voz ao locutor do discurso direto, divide-se em dois locutores, desdobra-se em dois "eus". Assim, temos um coronel Ponciano narrador e um outro coronel Ponciano que recebe a voz do narrador, apresentado-se como locutor nos discursos diretos.

No tocante especificamente ao romance O Coronel e o Lobisomem, antes de iniciarmos sua leitura, encontramos em seu prefácio o seguinte comentário tecido por Rachel de Queirós:

O romancista (...) conseguiu fazer com que o dito leitor (...) se esquecesse completamente de que havia um autor de permeio e tratasse o protagonista como figura de vivente, como homem, como gente, apaixonante e de carne, tal como nós.

Encerrada a leitura da obra, voltamos ao seu prefácio e percebemos que deveria ser este o ângulo visual a ser assumido por nós. Uma vez que o romance, considerado como um todo, é um único enunciado - o que Bakhtin (1992B) chama de enunciado secundário - temos, nele, o discurso primário que se integra à realidade de sua vida artístico-literária.

Nesse sentido, limitar-nos-emos à obra literária, centrando nossas atenções no discurso do narrador e nos discursos das personagens relatados, em forma de discurso direto e indireto, pelo narrador - locutor primeiro - sujeito falante que manifesta sua individualidade apresentando-nos uma visão de mundo centrada em seu "eu".

No desenrolar da leitura, percebemos a amplitude do corpus discursivo do protagonista; sendo ele um sujeito que interage em 
variados segmentos sociais, além da constante exaltação de seu "eu", apresenta um riquíssimo caráter polifônico. Assim, temos seu comportamento lingüístico enquanto coronel - autoridade de cunho legal -; enamorado - no tocante às mulheres, procura mostrar-se fino e delicado -; culto - ao tratar com letrados ("bomens da lei"), apresenta-se erudito -; menino frágil que precisa de colo - é o menino da Francisquinha (criada com quem esteve desde a infância e que representa a figura da mãe) -; o senhor dono de criados que são seus servos; e o religioso - cristão devoto de santos.

No tocante ao modelo teórico em que respaldaremos nosso estudo, iniciaremos levantando os elementos categoriais que marcam na enunciação a presença da subjetividade do locutor, baseandonos nos estudos de Benveniste. Em um segundo momento, aplicaremos os estudos apresentados por Bakhtin, que tratam da interação do indivíduo no contexto social/ideológico.

\section{A PRESENÇA DA SUBJETIVIDADE NO DISCURSO}

Segundo Benveniste (1989A), a linguagem humana é multiforme e heteróclita, ela pertence ao domínio individual e ao domínio social e a língua se apresenta, sob todos os seus aspectos, como uma dualidade: ela é uma instituição social produzida pelo indivíduo e é um discurso contínuo - se compõe por unidades fixas. Já o domínio lingüístico se circunscreve pela compreensão de sistemas extralingüísticos homólogos ao da língua que têm o caráter de serem signos.

Nesse sentido, Benveniste afirma também que o papel dos signos lingüísticos é o de representar, tomar lugar de outra coisa evocando-a a título de substituto. Assim, a língua se manifesta pela enunciação que contém referência a uma situação dada; falar é sempre falar de.

As funções da língua aparecem claramente quando a observamos no exercício da linguagem que se concretiza por meio da 
produção do discurso. Vale ressaltar, portanto, que, no tocante ao discurso, produzido por meio de uma linguagem, todo homem se coloca, em sua individualidade, enquanto "eu" em oposição a "tu" e "ele". Desta forma, em toda língua e a todo momento, aquele que fala se apropria deste "eu", que introduz a presença da pessoa, elemento que, por sua vez, possibilita a existência da língua.

No momento da enunciação, o pronome "eu", de um elemento de um paradigma, se transforma em uma designação única e produz, a cada vez, uma nova pessoa, revelando, pois, experiências da subjetividade daquele que realiza o discurso.

Para Benveniste (1991B) o verbo e o pronome são as únicas classes de palavra submetidas à categoria de pessoa. Os verbos podem remeter sempre a três pessoas: "eu", "tu" e "ele". O "eu" designa aquele que fala e implica, ao mesmo tempo, um enunciado sobre o "eu"; na segunda pessoa, "tu" é necessariamente designado por "eu"; a terceira pessoa, porém, fora do "eu" e do "tu", é uma não-pessoa. O "eu", em oposição ao "tu", é interior ao enunciado (pessoa subjetiva). O "tu", exterior ao enunciado, é a pessoa não subjetiva.

O sujeito falante (enunciatário) ao se declarar locutor e assumir a língua, implanta o outro diante de si. Na enunciação temos, como instrumento de realização, além do locutor, os seguintes elementos: a língua, que se encontra empregada para a expressão de uma certa relação com o mundo; a referência, parte integrante da enunciação; a posição do locutor; a implantação do alocutário; e temos também a emergência dos índices de pessoa que se produz pela enunciação. Assim sendo, o termo "eu" denota o indivíduo que profere a enunciação, e o termo "tu" o indivíduo que está presente como alocutário.

Benveniste (1989A: 83) afirma que "a enunciação supõe a conversão individual da língua em discurso". A enunciação conduz a um aspecto de semantização em que aparece a significância, por meio da referência, através do ato individual de utilização da língua; o que "introduz em primeiro lugar o locutor como parâmetro nas condições necessárias da enunciação". 
Mais incisivamente, encontramos, em Benveniste (1989B: 101), a seguinte colocação: “... cada um fala a partir de si. Para cada falante o falar emana dele e retorna a ele, cada um se determina como sujeito com respeito ao outro ou aos outros". E em Benveniste (1991A: 84), temos: "O sujeito se serve da palavra e do discurso para representar-se a si mesmo, tal como quer ver-se, tal como chama o outro a comprovar". Dessa maneira, a linguagem é utilizada "como palavra convertida nessa expressão da subjetividade iminente e evasiva que constitui a condição do diálogo". Assim, o sujeito libertase e se mostra da maneira que lhe for conveniente diante do outro.

Numa concepção benvenistiana, no romance escolhido para análise, o discurso está centrado no "Ego", a começar pela pessoa verbal. O texto é narrado em primeira pessoa, o "eu" designa aquele que fala e implica, ao mesmo tempo, um enunciado sobre o "eu". A língua é colocada em funcionamento através da enunciação, o que leva à produção do discurso emanado de um locutor que manifesta sua posição por meio de enunciados - unidades do discurso - específicos. Para Benveniste (1989A: 84), "a presença do locutor em sua enunciação faz com que cada instância de discurso constitua um centro de referência interno".

Assim, o locutor, ao se servir da língua para influenciar o comportamento do alocutário, dispõe, para este fim, de um aparelho formal de funções composto por enunciados e formas lingüisticas que marcam sua subjetividade.

Das marcas da subjetividade no discurso do coronel Ponciano de Azeredo Furtado, em uma concepção benvenistiana, temos algumas tipologias de enunciações, ou apenas categorias lingüísticas nas enunciações (estas últimas são algumas categorias gramaticais específicas), conforme passamos ilustrar:

a) Interrogação

- Como vai o desalmado? Ainda está muito cantador? (p.263).

- Que milagre é esse, Seu Fontainha? Deixou a política do Dr. Nogueira? (p.244). 
Sendo a interrogação uma enunciação construída para suscitar uma resposta, transcrevemos aqui duas indagações feitas pelo coronel em seu discurso. Na primeira, vemo-lo interrogando a João Fonseca sobre um sabiá laranjeira. A segunda interrogação, destinada ao seu secretário Artur Fontainha, se deu quando Fontainha o havia deixado e retorna em seu escritório por alguns momentos para pedir dinheiro para a campanha eleitoral de Pernambuco. As duas foram construídas por meio do discurso direto e são, no discurso, fortes marcas da subjetividade do locutor, pois representam manifestações do interior do indivíduo.

b) Asserção: Sendo um elemento que visa a comunicar uma certeza, há asserções presentes em todo o texto, afinal nosso protagonista não tem dúvidas, se sente informado e preparado sobre todo e qualquer assunto e/ou situação. Como exemplos de asserção podemos destacar, entre outros, os seguintes:

Deixei a Rua dos Frades nos cascos da alegria. A mulher de Nogueira era peça domada, caída de sentimento, de quase verter lágrima no meu brim. (p.189).

A bem dizer, encontrei Santo Amaro no debaixo da cama, o povo todo sumido, uns outros espiando de longe, como se o coronel viesse em missão de passar todo mundo nas armas. (p.153).

Na primeira asserção acima apresentada, temos o coronel se mostrando seguro dos sentimentos de dona Esmeraldina, senhora por quem se apaixonou; já na segunda, vemo-lo se firmando como autoridade em cumprimento de uma missão.

c) Pronomes pessoais, demonstrativos. Como exemplo de seu uso pelo coronel Ponciano de Azeredo Furtado, podemos observar o termo em destaque no fragmento abaixo:

Sem sair do Livro Verde ("Desta saleta onde vosmecê, Seu Fontainha, tem o rabo"), eu andava no concernente de todos os tidos e havidos em Mata Cavalo... (p.223). 
Ao apontar a saleta, o coronel informa que está envolvido por aquele lugar, mas não perdeu o controle de suas propriedades rurais.

d) Temos também a presença de enunciado com sentido expressivo em forma de exclamação, que indica entonação:

Com uma lambada de assobio, que zuniu ferina, desmanchei, no costado dele, todas as ofensas recebidas da corja dos Nogueira:

- Toma, filho de uma cadela! (p.287).

O enunciado sublinhado indica uma entonação em um momento de cólera, o narrador apresenta-se como locutor, utilizase do discurso direto e se comporta como se estivesse vingando-se, em um só momento, de toda a família Nogueira.

Essas proposições (acima destacadas) refletem o comportamento fundamental do coronel Ponciano de Azeredo Furtado falando e agindo pelo discurso sobre seus interlocutores, os quais the transmitem ou dele obtêm informações, ou ainda recebem ordens. Segundo Benveniste (1989A), estas proposições caracterizam as funções interumanas do discurso que se imprimem nas modalidades de frase, correspondendo cada uma a uma atitude do locutor.

Como sujeito falante, serve-se da palavra e do discurso para representar-se a si mesmo. Utilizando-se da auto-representação, evidencia a categoria de auto-referência, através da qual se exalta e canta suas grandezas, conforme podemos observar através da leitura do fragmento abaixo.

- Amanhã, sem mais tardança, boto o coronel na estrada.

E já andava de mala arrumada, cavalo encilhado, quando o primo Azeredo implorou que eu desse um retardo na viagem, precisado que estava de meu tirocínio numa complicação de escrituras, por ser eu antigo aprendiz de escrivão e sujeito capaz de destorcer uma lei para o vento que bem entendesse. (p.92).

No primeiro enunciado deste fragmento, o Coronel se posiciona como uma terceira pessoa, tornando-se, assim, o referente de seu próprio discurso. Desdobra-se em dois "eus" e olha para si 
mesmo; já no segundo, usa da primeira pessoa para lisonjear a si próprio, através da auto-estima. Na verdade, há o desdobramento de um "eu" em três "eus". Temos o narrador apresentando-se como um outro "eu" com voz - o locutor do discurso direto - e temos ainda uma terceira pessoa no discurso direto sem voz - apenas referida.

O Coronel Ponciano de Azeredo Furtado, ao efetuar a operação da referência, utiliza-se da auto-referência, coloca-se como uma terceira pessoa, e se torna o referente de seu próprio discurso. O uso do "ele" coloca-o como um referente fora do discurso; evidencia-se aí a fragmentação do sujeito através da evocação da presença de um outro "eu". Como exemplo, além do fragmento acima, podemos destacar, entre outros, passagens como:

Bem que eu apurava o coronel. Vinha a Mata-Cavalo em água de cheiro. (p.70).

Encontramos, ainda nesses fragmentos, uma situação na qual um "eu" é imputável a um outro "eu". Temos, nesse processo, uma dupla instância discursiva conjugada. Uma primeira instância de um "eu" locutor, que faz a referência, e uma outra instância contendo "eu" como referente.

Considerando as argumentações de Benveniste (1991C) que discute que é na linguagem e pela linguagem que o homem se constitui como sujeito, porque só a linguagem fundamenta a realidade, na sua realidade que é a do ser, o conceito de "ego", percebemos que nosso locutor indica uma forte determinação de se impor como sujeito. Podemos, então, afirmar que a realidade à qual o "eu" se remete é apenas uma realidade do discurso, pois, sendo somente na instância do discurso que o sujeito se define como a unidade psíquica, o coronel, nesse momento, assegurando a permanência de sua consciência, apresenta experiências que diz ter vivido, sua subjetividade é determinada através de seu status lingüístico. 


\section{A PRESENÇA DO EXTERIOR NO DISCURSO}

Relativamente à consciência subjetiva dos indivíduos de uma comunidade, existem as normas sociais que são sistemas de regras morais, jurídicas, estéticas, e outros. A língua, conforme nos chama a atenção Bakhtin (1992A), não se apresenta para a consciência do locutor como um sistema de formas normativas e imutáveis, já que a consciência subjetiva do locutor não se utiliza da língua como um sistema de formas fixas.

O locutor serve-se da língua para suas necessidades enunciativas concretas, utiliza-a, portanto, seguindo uma orientação do contexto em que se encontra no momento de realização da fala. Entretanto, os contextos não estão simplesmente justapostos como se fossem indiferentes uns aos outros, encontram-se em uma situação de interação e de conflito tenso e ininterrupto.

Nesse sentido, procuraremos, agora, centrar nossa análise do discurso da personagem, também narrador, Ponciano de Azeredo Furtado, no dualismo que encontramos na enunciação realizada por todo e qualquer sujeito. Esse dualismo comporta duas facetas: o conteúdo interior e sua objetivação exterior. Valendo-nos, primordialmente, do conceito de interação apresentado por Bakhtin (op. cit. A) - meio pelo qual o indivíduo se constitui como sujeito observaremos, então, a reflexão do mundo interior de nosso locutor em seu "auditório social", ressaltando as fronteiras de uma classe e de uma época bem definidas.

No tocante à objetivação exterior do conteúdo interior, Bakhtin (op. cit. A: 113) afirma que "a situação social mais imediata e o meio social mais amplo determinam completamente e, por assim dizer, a partir do seu interior, a estrutura da enunciação". E ao falar sobre a interação social do sujeito, argumenta que a expressão-enunciação é determinada pela situação social imediata e a enunciação é o produto da interação entre dois, ou mais, sujeitos socialmente organizados. Bakhtin (op. cit. A: 117) assegura que "não é do interior, do mais profundo da personalidade, que se tira a confiança 
individualista em si, a consciência do próprio valor, mas do exterior; trata-se da explicitação ideológica do meu status social". Diante dessas colocações, faz-se oportuno observar, no discurso, o status social do coronel Ponciano de Azeredo Furtado. Sendo um "coronel de patente", apresenta-se como único dono da palavra, conforme podemos perceber em passagens como:

- Seu Pereira, Seu Pereira! como é que tem a ousadia de tirar da cama um coronel de patente para um rebate falso de capivara? (p.44).

(...) Sujeito de tirocínio, manobrei na prudência. Fiz ver a Dona Esmeraldina (...) que Mata-Cavalo requeria ainda uns reparos e confortos... (p.224).

... por ser eu (...) sujeito capaz de destorcer uma lei para o vento que bem entendesse:

-É o que eu digo sempre. Em duas coisas ninguém pode com o primo Ponciano. Em rabo de saia e artimanha do Foro. (p.93).

Contudo, esse apresentar-se como único dono da palavra só é possível porque há uma estruturação social de sua personalidade, através da qual pretende firmar seu individualismo ideológico; pois é do exterior que se tira a consciência do próprio valor. Trata-se, conforme afirmamos, de uma explicitação ideológica de seu próprio status social, de sua posição econômica individual. Nesse sentido, Bakhtin (op. cit. A) afirma que o individualismo é uma forma ideológica particular da atividade mental do "nós" da classe burguesa.

Nos diálogos tomados como corpus para análise, bem como em todo o romance, o protagonista e narrador, coronel Ponciano de Azeredo Furtado, exprime sua personalidade e revela-se um produto da inter-relação social. Conseqüentemente, todas as suas atitudes, expressas através de seu discurso, destinam-se a mostrar seu status como sujeito em determinado âmbito social e, como sujeito de um determinado âmbito social, tem voz, faz-se locutor duas vezes, como narrador e como personagem. Assim, temos: 
Padre Malaquias, na sua cadeira de rodas, esperava por mim. Mandou intimação para que eu aparecesse na sacristia.

Chapéu no peito, pedi desculpas pelo desplante de trazer barulho de arma a Santo Amaro sem o seu devido consentimento. (...)

E sacudindo o rosário mandou que eu recolhesse a campeirada senão ele de boca própria dava as ordens. (p.154).

Pois digo que no corpo da discussão inventei uma raça de capim que no conhecimento de ninguém era chegada (...)

- Despachei Quintanilha para a herança de Mata-Cavalo munido de carta branca, com recomendação de não tirar o olho dos mourões. (p.19).

Bem que eu apurava o coronel. Vinha a Mata-Cavalo em água de cheiro. (p.70).

A leitura desses fragmentos evidencia, no discurso do nosso locutor, a presença de outros "eus" que contribuem para sua constituição como sujeito discursivo. Dessa maneira, em oposição às afirmações encontradas em Benveniste (op. cit.), destacam-se aos nossos olhos, marcas de sua heterogeneidade discursiva, o que resulta em uma polifonia caracterizada pela presença de várias vozes no discurso. Nesse aspecto, temos uma pluralidade do "eu" que se apresenta através do discurso, caracterizado pela presença dos seguintes sujeitos: um "eu" portador da patente militar que o faz conhecedor e obediente das leis e, ao mesmo tempo, se mostra cristão, pois é disciplinado por doutrinas religiosas. Em oposição a este eu disciplinado, há um "eu" valente, capaz de enfrentar, de armas em punho, as autoridades citadinas. Há ainda presente o "eu" um pouco mais pastor: o criador e possuidor de gado em propriedades rurais que, por sua vez, se opõe ao "eu" delicado e fino que se perfuma para visitar uma professora que passava alguns dias em Mata-Cavalo. Todos esses "eus" constituem o desdobramento de um primeiro desdobramento. Em um primeiro nível, temos o eunarrador e o eu-personagem; em um segundo nível, o eupersonagem que se desdobra em todos os "eus" destacados.

Nesse aspecto, podemos ressaltar também o uso do discurso direto. Sendo esta modalidade de discurso um meio para instaurar 
o outro diante de si, o coronel, muitas vezes, em sua pluralidade, se posiciona como um outro "eu" e estabelece rápidos diálogos com ele mesmo, conforme podemos observar na seguinte passagem:

- Amanhã, sem mais tardança, boto o coronel na estrada. (p.92).

Ao observarmos o comportamento lingüístico do Coronel Ponciano de Azeredo Furtado, conforme exemplificado anteriormente, contrariando as afirmações de Benveniste, devemos falar também de um fato social e não apenas de um ato individual interior, pois todo seu discurso é construído para exaltar-se e mostrar-se inteirado em determinado segmento social. Pretende, através de seu ato discursivo, apresentar-se capaz de interagir em todos os territórios sociais que possibilitem ação humana, uma vez que as fórmulas da vida cotidiana fazem parte do meio social. Assim, sua atividade mental tende para uma expressão externa plenamente realizada.

Bakhtin (op. cit. A: 125) discute que

a enunciação realizada é como uma ilha emergindo de um oceano sem limites, o discurso interior. As dimensões e as formas dessa ilha são determinadas pela situação da enunciação e por seu auditório. A situação e o auditório obrigam o discurso interior a realizar-se em uma expressão exterior definida, que se insere diretamente no contexto não verbalizado da vida corrente, e nele se amplia pela ação, pelo gesto ou pela resposta verbal dos outros participantes na situação de enunciação.

Nosso locutor se comporta de formas diferentes em diferentes situações discursivas, esforça-se para manter no exterior a complementaridade de seu interior. Às vezes, toma atitudes não verbais, quando sente que seu discurso não o levou a atingir o objetivo pretendido. A exemplo, temos:

Na confusão advinda, o moço da engenharia rapidinho, de cara barbeada de uma banda só, escapuliu da cadeira e ganhou a rua mais desarvorado do que o pai dos capetas em capela de santo. Foi meu cipó vingancista mostrar ao safado o tamanho do braço do coronel. Com uma 
lambada de assobio, que zuniu ferina, desmanchei, no costado dele, todas as ofensas recebidas da corja dos Nogueira:

- Toma, filho de uma cadela!

O engomadinho, ganindo em formato de cachorro espantado, embarafustou o rabo por um armarinho de fazenda, de ninguém saber como entrou e saiu. Aí cantei de galo:

- Esse vai mijar vermelho o resto do mês. (p.288).

Nesse momento da narrativa, Ponciano procura restabelecer seu status social de coronel, procura recuperar sua superioridade; como recurso, utiliza-se da força física. Temos, portanto, ações não verbais para a tentativa de estabelecimento de uma complementaridade entre interior - desejo de manter o status social - e exterior - receber o tratamento correspondente à sua posição imaginária.

A língua possibilita uma ação ininterrupta que se realiza através da interação verbal social entre seus interlocutores. Sendo o romance, objeto de que nos servimos para estudo, um fenômeno da vida literário-artística, e considerando que, conforme escreve Naves (1992: 151), "el mundo de la ficción literaria se propone utilizar la palabra en forma semejante a como la usa el mundo de la realidad en los intercambios sociales de tipo verbal", destacamos apenas aspectos internos à obra; elementos da vida cotidiana do prota-gonista e narrador, sujeito falante, que manifesta sua individualidade apresentando-nos sua visão de mundo, centrada em seu eu, constituído pela interação social.

\section{CONSIDERAÇÕES FINAIS}

A partir do que foi observado no discurso do Coronel Ponciano de Azeredo Furtado, podemos reafirmar que o sujeito reproduz no campo lingüístico o jogo imutável e conflituoso das relações sociais. E os enunciados, por sua vez, são produzidos pela interação da língua e a situação - contexto - do momento de sua produção, e se inscrevem em um sistema de apreciações sociais que constituem o campo discursivo. Tem-se, pois, um sujeito social pleno, não apenas um sujeito discursivo. Este último seria englobado pelo primeiro. 
No que concerne a esta questão, percebemos que o sujeito é resultado de uma estrutura complexa e, conforme discute AuthierRevuz (1982), baseando-se em Bakhtin e em releituras de Freud feitas por Lacan, há um descentramento do sujeito: um "eu" implica outros "eus" e o outro se apresenta como uma condição constitutiva do discurso do sujeito falante; afinal, um discurso se constitui através de outros discursos.

Nessa acepção, há uma ruptura do "eu" fundamentado na subjetividade como um interior face à exterioridade do mundo. Na verdade, a exterioridade é levada para o interior do sujeito. Dessa maneira, o sujeito discursivo poderá ser definido pela junção do exterior com o interior, conforme escreve Brandão (1995: 46), "o sujeito é ele mais a complementação do outro".

Assim, o protagonista de O Coronel e o Lobisomem, locutor tomado por nós como objeto de estudo, apresenta-se como um sujeito fragmentado (o que é inerente ao ser humano), uma vez que, conforme vimos, atua em diferentes segmentos sociais com os quais estabelece uma interação. Logo, seu discurso, ao mesmo tempo que o constitui como sujeito, é constituído de forma a possibilitar-lhe esta interação nos vários âmbitos sociais.

O locutor, ao se expressar, expõe, através de seu discurso, elementos que são exteriores, mas que foram absorvidos por esse locutor em sua constituição e que passaram a fazer parte dele.

Dessa forma, o coronel Ponciano de Azeredo Furtado, assim como todo e qualquer sujeito falante, apresenta uma homogeneidade discursiva (que faz parte de sua individualidade) e uma heterogeneidade (que o caracteriza como um "eu" agente social).

Estas características discursivas, sempre presentes no discurso do sujeito falante, são constituídas pela interação social verbal do sujeito com o mundo sócio-cultural no qual se encontra. 


\section{REFERÊNCIAS BIBLIOGRÁFICAS}

AUTHIER-REVUZ, Jacqueline. Hétérogénéité montrée et hétérogénéité constitutive: éléments pour une approche d l'outre dans le dicours. In: DRLAV. Paris, centre de Recherches de l'Université de Paris III, 1982.

BAKHTIN, M. Marxismo e Filosofia da Linguagem. Trad. Michel Lahud e Yara Frateschi Vieira. São Paulo: HUCITEC, 1992A.

Estética da criação verbal. Trad. Maria Ermantina G. G. Pereira. São Paulo: Martins Fontes, 1992B.

BENVENISTE, Emile. Observações sobre a função da linguagem na descoberta freudiana. In: Problemas de Lingüística Geral I. Trad. Maria da Glória Novac \& Maria Luiza Neri. São Paulo: Pontes, 1991A.

Estrutura das relações de pessoa no verbo. In: Problemas de Lingüística Geral I. Trad. Maria da Glória Novac \& Maria Luiza Neri. São Paulo: Pontes, $1991 \mathrm{~B}$.

. Da subjetividade na linguagem. In: Problemas de Lingüistica Geral I. Trad. Maria da Glória Novac \& Maria Luiza Neri. São Paulo: Pontes, 1991C.

. O aparelho formal da enunciação. In: Problemas de Lingüistica Geral II. Trad. Eduardo Guimarães et al. São Paulo: Pontes, 1989A.

. Estrutura da língua e estrutura da sociedade. In: Problemas de Lingüística Geral II. Trad. Eduardo Guimarães et al. São Paulo: Pontes, 1989 B.

BRANDÃO, Helena H. Naganime. Introdução à Análise do Discurso. Campinas: Ed. da UNICAMP, 1995.

CARVALHO, José Cândido de. O Coronel e o Lobisomem. 35 ed. Rio de Janeiro: José Olympio, 1985.

FOUCAULT, Michel. L'Archéologie du savoir. Paris: Gallimard, 1969.

MAINGUENEAU, Dominique. Novas tendências em Análise do Discurso. Campinas: Pontes, 1993.

NAVES, María Del Carmen Bobes. El dialogo-Estudio pragmático, lingüístico y literario. Madrid: Editorial Gredos, 1992.

QUEIRÓS, Rachel de. É o gênio da língua que baixou. In: CARVALHO, José Cândido. O Coronel e o Lobisomem. 35 ed. Rio de Janeiro: José Olympio, 1985. 